\title{
Controlled release of ibuprofen from polymeric nanoparticles
}

\author{
Sara Shehata, Christopher J. Serpell*, and Stefano C. G. Biagini*. \\ Supramolecular Interfacial Synthetic Chemistry Group, School of Physical Sciences, \\ Ingram Building, University of Kent, Canterbury CT2 7NH, UK. \\ E-mail: s.biagini@kent.ac.uk; c.j.serpell@kent.ac.uk
}

Smart polymeric systems are required that are able to release a therapeutic drug with controlled delivery. Herein we investigated the $\mathrm{pH}$ triggered release of ibuprofen from a polymeric nanoparticle system prepared using ring-opening metathesis polymerisation. The co-polymerisation of ibuprofen and poly(ethylene)glycol monomers followed by self-assembly produced a nanoparticle system that was shown to be stable at neutral pH but releases ibuprofen in alkaline conditions.

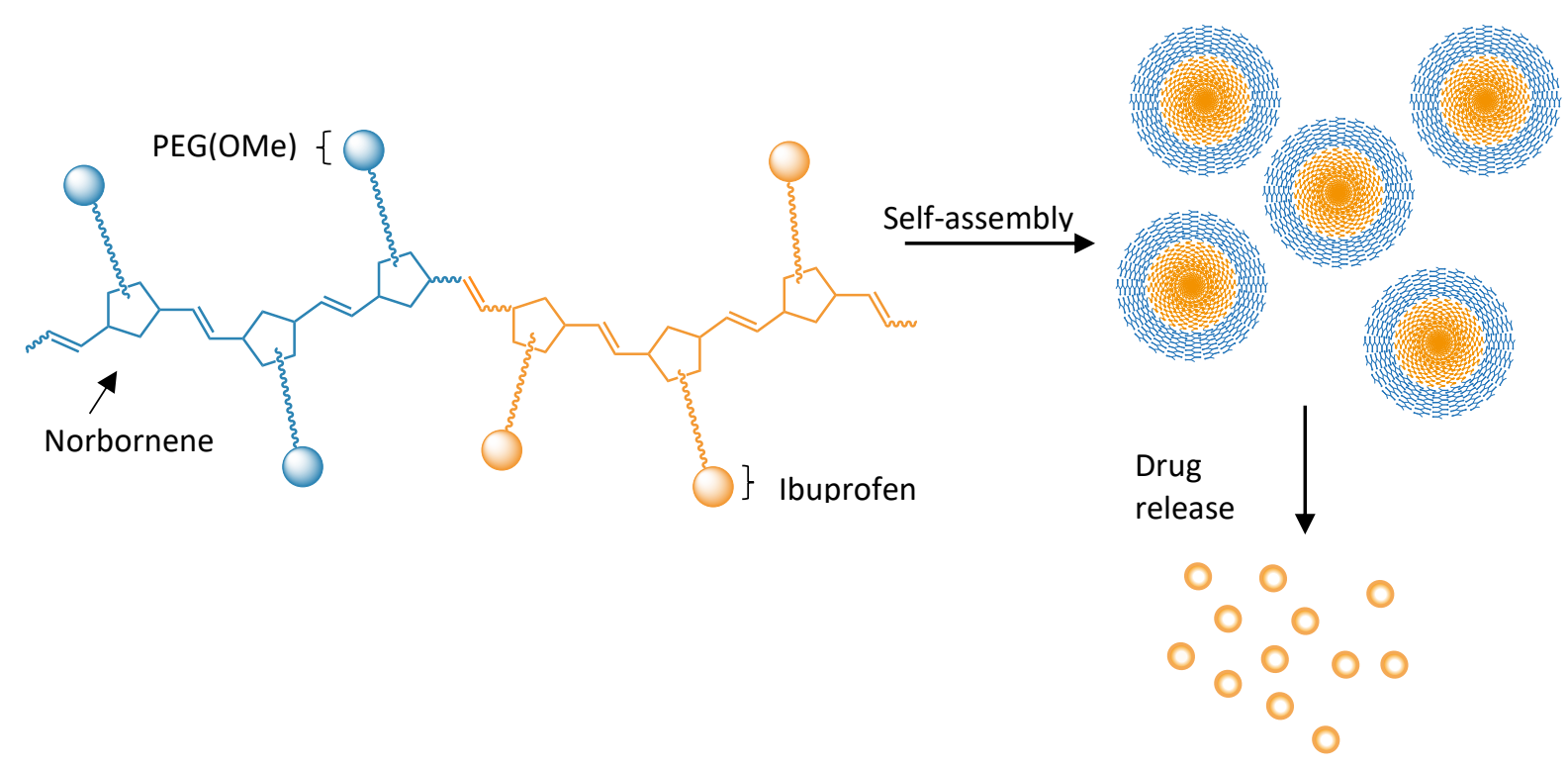

\section{Introduction}

Non-steroidal anti-inflammatory drugs (NSAIDs) possess analgesic, antipyretic and anti-inflammatory properties and are amongst the most widely prescribed drugs worldwide. ${ }^{1}$ Pain relief is the primary clinical use for NSAIDs but the well-known association between inflammation and cancer has resulted in numerous investigations of NSAIDs for cancer prevention and treatment. Studies in various types of breast cancers, including prostrate ${ }^{2}$, breast $^{3}$, colorectal ${ }^{4,5}$ and ovarian $^{6}$ cancers indicate a positive effected linked to NSAID use. NSAIDs typically act by blocking the cyclooxygenase (COX) enzyme which is key in the synthesis of prostaglandins (PGs) which are required for the vasodilation associated with inflammation. There are however also epidemiological studies that contraindicate NSAID use which are associated with increased cancer risks, especially renal ${ }^{7}$, although the mechanism of action is unclear ${ }^{1}$. Furthermore NSAIDs have been associated with unwanted nausea and dyspeptic symptoms including ulcers $^{1,8}$ and internal bleeding ${ }^{9}$. These latter complications are related to the oral ingestion of NSAIDs and we therefore wished to investigate a polymer approach for the delivery of these drugs ${ }^{10}$ for tumour therapy. 
The field of polymer therapeutics spans several decades and works on the development of polymerdrug systems that rely on a degradable or bio-degradable process to release a drug from a polymer ${ }^{11}$. There are several advantages in using these poly-prodrug systems, such as an increase in the drug water solubility, an enhancement of drug bioavailability, protection of the drug during its circulation to the site of action and an improvement in pharmacokinetics ${ }^{12,13}$. In cancer therapy the enhanced permeation and retention (EPR) effect is also a common property associated with therapeutic macromolecules ${ }^{14,15}$ although this effect is questioned in human cell studies ${ }^{16}$. Having previously made a pure drug platform from salicylic acid ${ }^{17}$, we were interested in utilising the ring opening metathesis polymerisation (ROMP) process as a means of approaching a controlled drug release polymer system. The exquisite control that ROMP affords in preparing well-controlled functionally dense polymers and copolymers ${ }^{18,19}$ and their resulting self-assembly has led to several examples of bio-related and therapeutic ROMP polymers ${ }^{20-26}$. Chemically degradable ROMP polymers, in other words when the mechanism of drug release is a chemical process such as ester hydrolysis and not a biological process, is an area that is gaining more attention ${ }^{27-29}$. Previous work in our laboratories has shown that the copolymerisation of a polyethelene glycol (PEG) moiety in peptide derived ROMP polymer leads to self-assembled molecular architectures ${ }^{30,31}$ and we were interested in investigating the stability and release of a non-steroidal anti-inflammatory drug (NSAID), namely ibuprofen, from a ROMP-PEG polymer systems. Nanoparticles derived from ROMP-PEG polymers have been shown to exhibit good stealth properties in tumour therapy studies ${ }^{27}$ and the excellent living control polymerisation of ROMP allows for the post-released scaffold to be under $45 \mathrm{kDa}$, a requirement for renal excretion ${ }^{32}$. For this study we were considered four environments: aqueous, phosphate buffered saline (PBS), foetal bovine serum (FBS), pig liver esterase (PLE) and basic (2M NaOH in water).

\section{Results and Discussion}

\section{Monomer synthesis}

The monomers required for this investigation are not commercially available. Condensation reactions with the exo-carbic anhydride derivative 1 were chosen as these lead to symmetrical norbornene derivatives which minimise head to tail effects. The norbornene PEG-derivative 2 was prepared in a similar route to a previously reported methodology within the group ${ }^{31}$, whereas the ibuprofen derivative 4 was prepared from $\mathrm{N}$-(hydroxypentanyl)-cis-5-norbornene-exo-2,3-dicarboximide $3^{33}$, (Scheme 1). 
<smiles>O=C1OC(=O)C2C3C=CC(C3)C12</smiles>

1<smiles>COCCOC(=O)CN1C(=O)C2C3C=CC(C3)C2C1=O</smiles>

2 $\mathrm{n}=12$ (average)

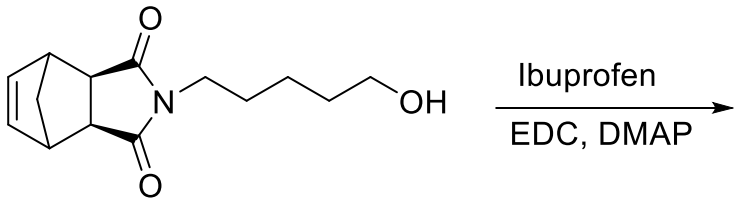

3<smiles>CC(C)Cc1ccc(C(C)C(=O)OCCCCCN2C(=O)C3C4C=CC(C4)C3C2=O)cc1</smiles>

4
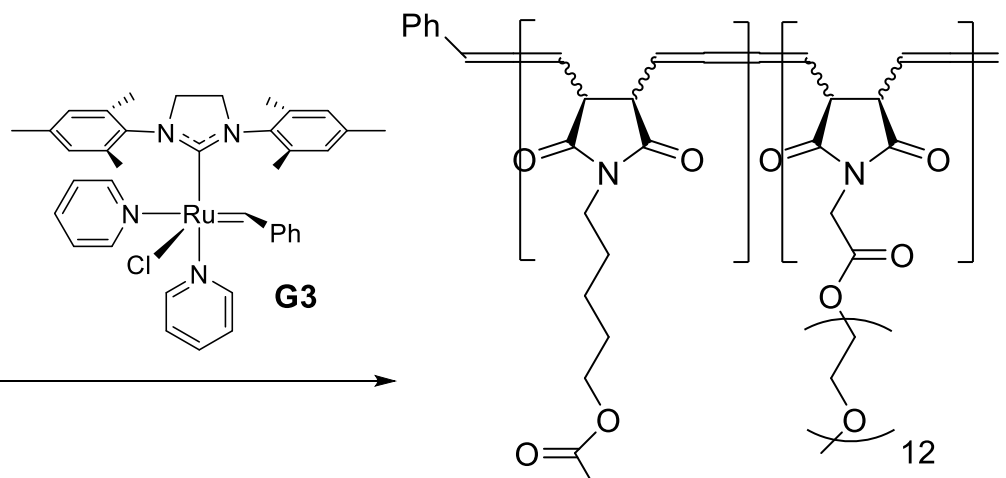

Figure 1 Synthesis of PEG-Ibuprofen copolymers

\section{Synthesis of polymers}

The monomers 2 and $\mathbf{4}$ were polymerised respectively, using the commercially available Grubbs $\mathrm{G} 3$ initiator $^{34}$ in THF at room temperature and were terminated with ethyl vinyl ether.

The individual homopolymers were readily formed and after isolation they were characterised by proton NMR and GPC (data presented in Table 1). The polydispersity of the PEG polymer poly- 2 was slightly higher than for poly-4 and may be a reflection of the PEG chain length of the monomer which is itself an average distribution.

Table 1: polymerisation characteristics for poly-2 and poly-4.

\begin{tabular}{l|lllllllll} 
& Polymer & $\begin{array}{l}\text { Reaction } \\
\text { time }\end{array}$ & $\begin{array}{l}\text { Monomer } \\
\text { conversion } \\
(\%)\end{array}$ & $\begin{array}{l}\text { Yield } \\
(\%)\end{array}$ & $\begin{array}{l}M_{n} \\
\text { Theoretical }\end{array}$ & $\begin{array}{l}M_{n} \\
{ }^{H} H M R\end{array}$ & $\begin{array}{l}M_{n} \\
G P C\end{array}$ & $\begin{array}{l}M_{w} \\
G P C\end{array}$ & $\begin{array}{l}\theta \\
\left(M_{w} / M_{n}\right)\end{array}$ \\
\hline $\begin{array}{l}\text { G3 } \\
\text { initiator }\end{array}$ & Poly-2 & $5 \mathrm{~min}$ & $>99$ & 92 & 14852 & 16947 & 10984 & 14229 & 1.36 \\
& Poly-4 & $5 \mathrm{~min}$ & $>99$ & 98 & 8752 & 8755 & 11116 & 13640 & 1.27
\end{tabular}


To obtain the block co-polymer poly(4-b-2), the exo-norbornenyl ibuprofen monomer 4 was firstly polymerised using a ratio of monomer to G3 initiator of 20:1 and dry DCM as solvent. After 10 minutes an equimolar quantity of exo-norbornenyl PEGOMe monomer 2 was added to the reaction mixture giving an overall ratio of monomer to initiator of 40:1. Statistical copolymer poly(4-co-2) was synthesised by adding both of monomers ( $1: 1$ molar ratio) at the same time, into the G3 initiator solution. In each case the polymerisation was terminated by adding ethyl vinyl ether and the pure polymer was obtained by precipitation with diethyl ether (Figure 1).

It was found that both copolymers poly(4-b-2) and poly(4-co-2) possessed a polydispersity index lower than 1.4 and a number average molecular weight, $M_{n}$ that is comparable with the theoretical one. For the block copolymer poly(4-b-2) it was also possible to estimate the average molecular weight from end group analysis from the proton NMR.

Table 2: polymerisation characteristics of block and statistical copolymer derived from 2 and 4.

\begin{tabular}{|c|c|c|c|c|c|c|c|c|}
\hline Polymer & $\begin{array}{l}\text { Yield } \\
\text { (\%) }\end{array}$ & $\begin{array}{l}\% \\
P E G\end{array}$ & $\begin{array}{l}\% \\
\text { Ibuprofen }\end{array}$ & $\begin{array}{l}M_{n} \\
\text { Theoretic }\end{array}$ & $\begin{array}{l}M_{n} \\
{ }^{1} H \text { NMR }\end{array}$ & $\begin{array}{l}M_{n} \\
G P C\end{array}$ & $\begin{array}{l}M_{w} \\
G P C\end{array}$ & $\begin{array}{l}\oplus \\
\left(M_{w} / M_{n}\right)\end{array}$ \\
\hline Poly(4-b-2) & 78 & 36 & 64 & 21895 & 24632 & 19318 & 24905 & 1.29 \\
\hline Poly(4-co-2) & 76 & 37 & 63 & 22017 & n.a. & 19263 & 26191 & 1.36 \\
\hline
\end{tabular}

\section{Self-assembly of block and statistical copolymer}

Self-assembly of the copolymers mentioned above were obtained by dissolving the polymer $(<10 \mathrm{mg})$ in $1 \mathrm{~mL}$ of acetone, and deionised water was added dropwise, over a prolonged time to the stirred solution to give a polymer with a final concentration of $1 \mathrm{mg} / \mathrm{mL}$. The aggregate solution was subsequently transferred into a dialysis membrane, sealed and dialysed against distilled water for 24 hours to remove any traces of the organic solvent. The self-assembly was then analysed by DLS (Dynamic Light Scattering) and TEM (Transmission Electron Microscopy). DLS data was recorded using a polyphospholipid refractive index of 1.45 .

Figure 2 shows the DLS particle distribution for the block copolymer poly(4-b-2) in acetone, and of the statistical copolymer poly(4-co-2) also in acetone. This latter copolymer presents, as expected, a different distribution of the particle size; the largest peak $(67 \%$ by intensity) is for particles at $13 \mathrm{~nm}$. Because of the random distribution of the PEG and ibuprofen side chains tethered to the norbornene backbone, we interpret this as the polymer folding in on itself, forming single chain nanoparticles. A small amount of these nanoparticles (32\%) form random aggregates of a bigger size $(230 \mathrm{~nm})$ that precipitate in solution. TEM analysis of poly(4-co-2) confirmed an absence of

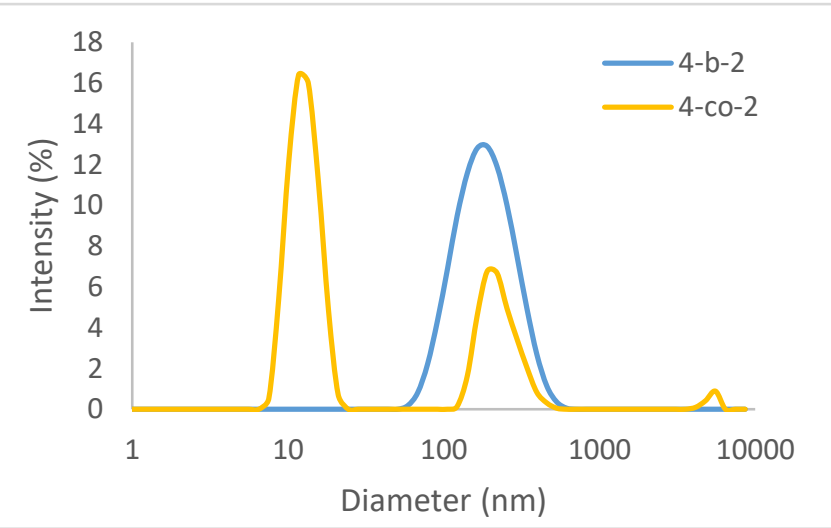

Figure 2: DLS particle size distributions of block and statistical copolymers. ordered self-assembly. 
The block copolymer, instead, behaves as a non-ionic amphiphilic polymer and in water forms particles in the size range of $50-600 \mathrm{~nm}$ as shown in Figure 6 with an average diameter of $196 \mathrm{~nm}$ in acetone.

The self-assembled morphologies of the copolymers were studied using TEM. Samples were analysed on Formvar coated copper grids, to which a negative stain of uranyl acetate was added, that allows for better contrasting of low molecular weight atoms $(\mathrm{C}, \mathrm{H}, \mathrm{N})$ under the electron beam.

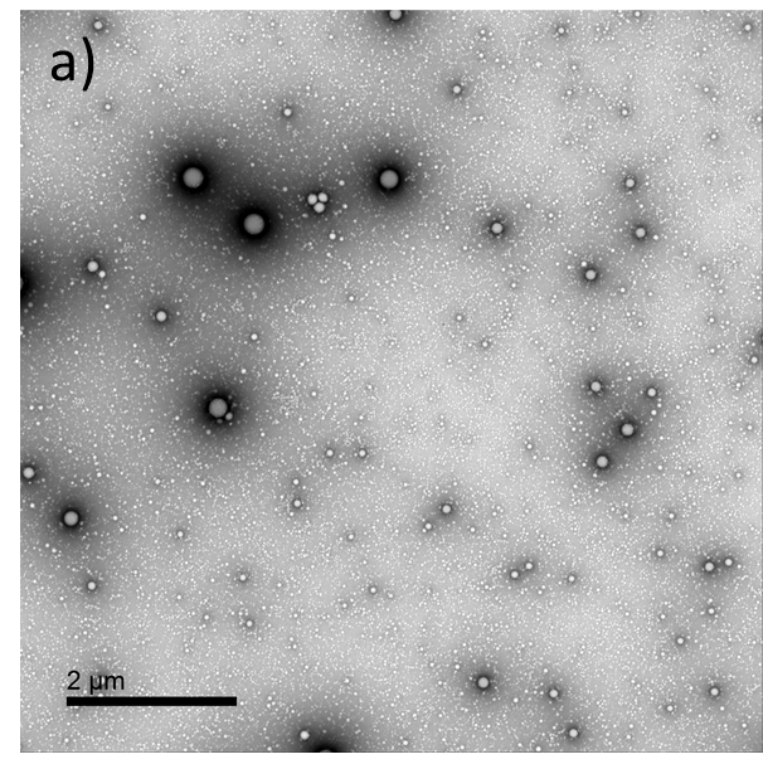

b)

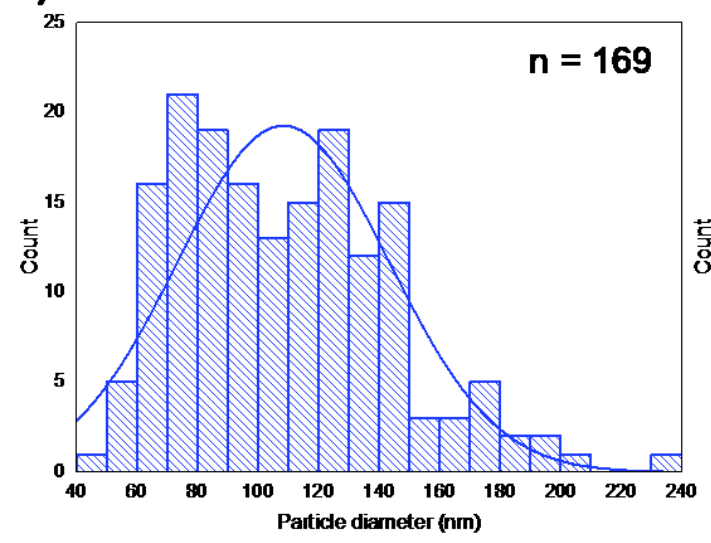

c)

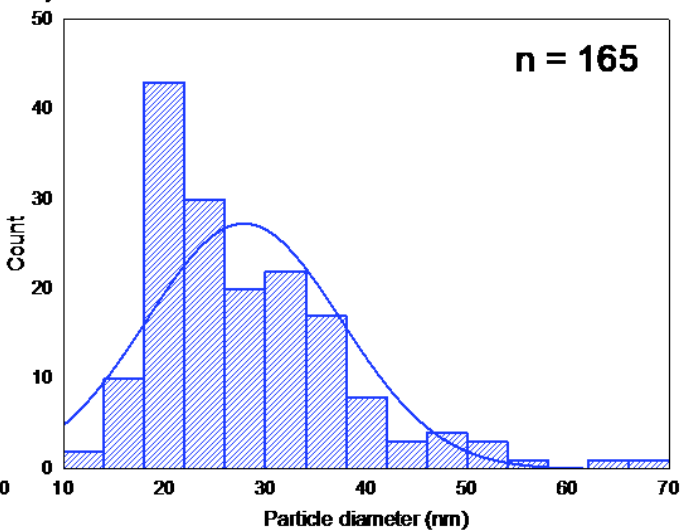

Figure 3: a) TEM image of block copolymer poly(4-b-2) ; b) distribution of the larger particles of image (a); d) distribution of the smaller particles of image (a).

Figure 3a shows the TEM images obtained for the block copolymer poly(4-b-2). The image seems to reveal the presence of two different morphologies which can be considered vesicles and micelles. Figure $3 b$ and $3 c$ indicate that the copolymer poly $(4-b-2)$ has a large distribution of particle size which ranges from $40 \mathrm{~nm}$ to $240 \mathrm{~nm}$. Examining the histograms in more detail, it is possible to identify, for each plot, two different particle distributions. For example, in Figure $3 \mathrm{~b}$, there are two distributions centred at $70 \mathrm{~nm}$ and $120 \mathrm{~nm}$ respectively. These results do not entirely correspond to the DLS measurements, which provide a bigger average diameter, as is common due to the solvation sphere measured by DLS, and the compacting effect of the vacuum in TEM. Furthermore, Figures $3 \mathrm{c}$ indicates that the formation of spherical micelles is dominant, and they possess an average diameter of $30 \mathrm{~nm}$. This result is in agreement with the calculations made using computational software, which afforded a 
repeating unit length of $0.617 \mathrm{~nm}$ that multiplied by the degree of polymerisation ( $D P=40$ ) gave a predicted particle radius of $25 \mathrm{~nm}$.

\section{In vitro release studies}

Block copolymer poly(4-co-2) $(200 \mu \mathrm{g})$ was placed into vials and $200 \mu \mathrm{L}$ solutions of $2 \mathrm{M} \mathrm{NaOH}$ in water, phosphate buffered saline (PBS), foetal bovine serum (FBS), pig liver esterase (PLE) and water were added to different sets of vials. The samples were incubated at 40 degrees in a thermocycler. Each sample was removed at predefined time points $(2 \mathrm{~h}, 4 \mathrm{~h}, 8 \mathrm{~h}, 24 \mathrm{~h}, 48 \mathrm{~h}, 96 \mathrm{~h})$, frozen and analysed afterwards by HPLC. A gradient processing method was used, starting from $20 \%$ methanol in water with $0.1 \%$ of formic acid. Samples $(10 \mu \mathrm{L})$ were run at $35^{\circ} \mathrm{C}$ at a flow rate of $2 \mathrm{~mL} / \mathrm{min}$. Absorbance was monitored at $\lambda=225 \mathrm{~nm}$. The instrument was calibrated using standard solutions of ibuprofen in methanol $(50,100,150,200,250$ ppm).

Figures $4 a$ and $4 b$ illustrate the release of ibuprofen using basic conditions: Figure $4 a$ shows the hydrolysis of ibuprofen using $\mathrm{NaOH}$ in water. It is possible to distinguish the characteristic peak of ibuprofen at a retention time around 3 minutes and 20 seconds. It is evident from the graphs, that ibuprofen can be slowly released over an extended duration of at least 4 days. By a prior calibration of the instrument, it is also possible to quantify the concentration of the released drug (Tables 4) which after $96 \mathrm{~h}$ is in agreement with the theoretically expected value for quantitative hydrolysis.

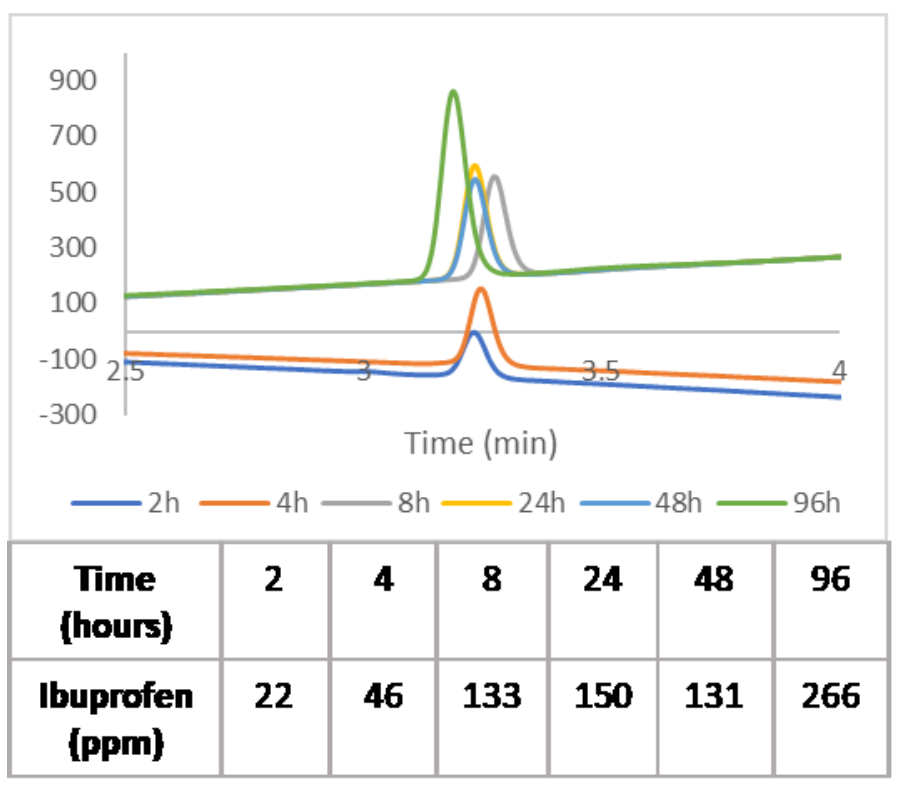

Figure 4: release study of ibuprofen with $2 \mathrm{M} \mathrm{NaOH}$ in water. Chromatogram and the table including the concentration of ibuprofen released during time.

As mentioned above, the hydrolysis of ibuprofen from block copolymers was investigated also using media that can mimic physiological conditions, such as PBS, FBS and PLE. By HPLC analysis, it appears that the polymer conjugate is stable as none of these media release ibuprofen at a temperature of 40 ${ }^{\circ} \mathrm{C}$. This suggests a polymer conformation which causes ibuprofen to be placed within the micelles where the proteins cannot hydrolyse the ester bond.

\section{Conclusion}

In summary we have shown that the block copolymerisation of norbornene monomers functionalised with polyethylene glycol and ibuprofen leads to the synthesis of a polymer which in an aqueous environment self-assembles to a nanoparticle system which in turn in an alkaline environment will release ibuprofen over a period of up to four days. Further work will explore different linkages between 
the polymer backbone and the drug with the aim of inducing controlled release in the presence of specific physiological environments.

\section{Acknowledgedments}

This work was supported by the School of Physical Sciences, University of Kent Graduate Training Scheme, and by the EPSRC Doctoral Training Programme. We gratefully acknowledge Dr E. R. Clark and $\operatorname{Dr}$ A. Morrell for advice and help with NMR, and LC and GC analysis respectively; and L. Birchall for help with the synthesis of compound 1.

\section{Author Information}

\section{Corresponding authors}

e-mail: s.biagini@kent.ac.uk; c.j.serpell@kent.ac.uk

Notes

The authors declare no competing financial interests. All authors have given approval to the final version of the manuscript.

ORCID ${ }^{\circ}$

Stefano C. G. Biagini: 0000-0002-4713-5127

Christopher J. Serpell: 0000-0002-2848-9077

Sara Shehata: 0000-0002-7663-5550

\section{References}

1 R. S. Y. Wong, Adv. Pharmacol. Sci., 2019, 1-10.

2 Y. Liu, J. Q. Chen, L. Xie, J. Wang, T. Li, Y. He, Y. Gao, X. Qin and S. Li, BMC Med., 2014, 12, 55.

3 T. Dierssen-Sotos, I. Gómez-Acebo, M. de Pedro, B. Pérez-Gómez, S. Servitja, V. Moreno, P. Amiano, T. Fernandez-Villa, A. Barricarte, A. Tardon, M. Diaz-Santos, R. Peiro-Perez, R. MarcosGragera, V. Lope, E. Gracia-Lavedan, M. H. Alonso, M. J. Michelena-Echeveste, A. GarciaPalomo, M. Guevara, G. Castaño-Vinyals, N. Aragonés, M. Kogevinas, M. Pollán and J. Llorca, BMC Cancer, 2016, 16, 660.

5 S. Friis, A. H. Riis, R. Erichsen, J. A. Baron and H. T. Sørensen, Ann. Intern. Med., 2015, 163, 347-355.

6 B. Trabert, R. B. Ness, W. H. Lo-Ciganic, M. A. Murphy, E. L. Goode, E. M. Poole, L. A. Brinton, P. M. Webb, C. M. Nagle, S. J. Jordan, H. A. Risch, M. A. Rossing, J. A. Doherty, M. T. Goodman, G. Lurie, S. K. Kjær, E. Hogdall, A. Jensen, D. W. Cramer, K. L. Terry, A. Vitonis, E. V. Bandera, S. Olson, M. G. King, U. Chandran, H. Anton-Culver, A. Ziogas, U. Menon, S. A. Gayther, S. J. Ramus, A. Gentry-Maharaj, A. H. Wu, C. L. Pearce, M. C. Pike, A. Berchuck, J. M. Schildkraut and N. Wentzensen, J. Natl. Cancer Inst., 2014, 106, djt431.

$7 \quad$ T. K. Choueiri, Y. Je and E. Cho, Int. J. Cancer, 2014, 134, 384-396.

8 I. Cazacu, C. Mogosan and F. Loghin, Clujul Med., 2015, 88, 128-136.

9 L. A. G. Rodríguez, M. Martín-Pérez, C. H. Hennekens, P. M. Rothwell and A. Lanas, PLoS One, 2016, 11, e0160046.

10 K. E. Schmalenberg and K. E. Uhrich, Biomacromolecules, 2005, 6, 359-367.

11 N. Kamaly, B. Yameen, J. Wu and O. C. Farokhzad, Chem. Rev., 2016, 116, 2602-2663. 

526, 135-144.

21 S. C. G. Biagini, V. C. Gibson, M. R. Giles, E. L. Marshall and M. North, J. Polym. Sci. Part A Polym. Chem., 2008, 46, 7985-7995.

22 S. C. G. Biagini, R. G. Davies, V. C. Gibson, M. R. Giles, E. L. Marshall, M. North and D. A. Robson, Chem. Commun., 1999, 235-236.

23 S. C. G. Biagini, V. C. Gibson, M. R. Giles, E. L. Marshall and M. North, Chem. Commun., 1997, 1097-1098.

24 L. Pichavant, H. Carrié, M. N. Nguyen, L. Plawinski, M. C. Durrieu and V. Héroguez, Biomacromolecules, 2016, 17, 1339-1346.

25 S. Sutthasupa, K. Terada, F. Sanda and T. Masuda, J. Polym. Sci. Part A Polym. Chem., 2006, 44, 5337-5343.

26 J. M. Fishman, D. B. Zwick, A. G. Kruger and L. L. Kiessling, Biomacromolecules, 2019, 20, 10181027.

27 P. Bertrand, C. Blanquart and V. Héroguez, Biomolecules, 2019, 9, 60.

28 L. Pichavant, C. Bourget, M. C. Durrieu and V. Héroguez, Macromolecules, 2011, 44, 78797887.

29 S. Hou, D. M. Hoyle, C. J. Blackwell, K. Haernvall, V. Perz, G. M. Guebitz and E. Khosravi, Green Chem., 2016, 18, 5190-5199.

30 A. L. Parry, P. H. H. Bomans, S. J. Holder, N. A. J. M. Sommerdijk and S. C. G. Biagini, Angew. Chemie - Int. Ed., 2008, 47, 8859-8862.

31 S. C. G. Biagini and A. L. Parry, J. Polym. Sci. Part A Polym. Chem., 2007, 45, 3178-3190.

32 D. Smith, E. B. Pentzer and S. T. Nguyen, Polym. Rev., 2007, 47, 419-459.

33 Y. C. Teo and Y. Xia, Macromolecules, 2015, 48, 5656-5662.

34 M. S. Sanford, J. A. Love and R. H. Grubbs, Organometallics, 2001, 20, 5314-5318. 